\title{
Kinetic investigations into the possible cause of low serum histidine in rheumatoid arthritis
}

\author{
N G SITTON, ${ }^{1}$ J S DIXON ${ }^{1}$ C ASTBURY,
}

R J FRANCIS, ${ }^{2}$ H A BIRD, ${ }^{1}$ AND V WRIGHT ${ }^{1}$

From the ${ }^{1}$ Clinical Pharmacology Unit, Royal Bath Hospital, Harrogate and the Rheumatism Unit, $\overrightarrow{\vec{\omega}}$ Department of Medicine, University of Leeds, Leeds; and ${ }^{2}$ Roche Products Limited, Welwyn Garden City. Herts

SUMmARY To investigate the cause of low serum histidine in rheumatoid arthritis (RA) single oral and intravenous doses of L-histidine were administered to patients with active RA, and to ano equal number of age and sex matched control subjects. In the first study 13 patients and their controls received a $100 \mathrm{mg} \mathrm{kg}^{-1}$ dose of L-histidine as an aqueous slurry. Significant differences were seen in body weight, predose baseline serum histidine concentration, $\mathrm{C}_{\text {max }}, \mathrm{t}_{1 / 2}$, and area under curve, $\mathrm{AUC}_{0_{-} \infty}$. In a second study six patients and six controls each received a $50 \mathrm{mg} \mathrm{kg}^{-} \sum_{\frac{\mathrm{m}}{2}}$ dose of L-histidine both orally and intravenously on two separate occasions. The patients with RA had a lower baseline serum histidine concentration, a lower volume of distribution, and $\infty_{\infty}^{\circ}$ shorter plasma half life than the controls, but these differences were not statistically significant No difference was seen in bioavailability or clearance. Low serum histidine in RA is unlikely to be due to malabsorption from the gut, uptake by abnormal gut flora, or increased metabolism.

The concentration of free serum histidine (i.e., histidine + trace metals-histidine complexes) is significantly decreased in patients with rheumatoid arthritis (RA). ${ }^{1}$ Gerber has shown that serum histidine levels are related to disease activity in patients with RA.

One possible cause of this hypohistidinaemia is defective absorption from the gut, perhaps due to excessive uptake or metabolism by atypical gut flora. There is some evidence to suggest that patients with chronic polyarthritis have an intestinal flora with the occurrence of atypical strains of Clostridium perfringens type $\mathrm{A},{ }^{2}{ }^{3}$ for which tryptophan and histidine are essential amino acids. ${ }^{4}$ Bergstrom and Havermark showed that the jejunal mucosa of patients with RA had 5-10 fold greater histidine methyl esterase activity than a control group. ${ }^{5}$ Alternatively, there may be a fault in a specific amino acid transport system across the gut wall.

A second possible explanation for low serum histidine may be an increase in catabolism. Histidine can be degraded to glutamate by the urocanate

Accepted for publication 15 June 1987.

Correspondence to Dr J S Dixon, Clinical Pharmacology Unit, Royal Bath Hospital, Cornwall Road, Harrogate HG1 2PS. pathway, but can also be directly decarboxylated to histamine. Histamine is a well recognised mediato $\$$ of inflammation and therefore may be produced im large quantities in RA. In mammalian tissues the synthesis of histamine is catalysed by the enzymos histidine decarboxylase, which has a high specificity for histidine, as well as by non-specific aromatic $L=$ amino acid decarboxylase found in several anima tissues, e.g., kidney, brain, and liver. ${ }^{6}$

To shed some light on the cause of low serum histidine we have investigated the pharmacokinetics of L-histidine in two histidine loading studies it patients with RA, and in age and sex matche重 normal controls.

\section{Patients and methods}

All patients had classical or definite RA (America保 Rheumatism Association criteria) ${ }^{7}$ and active dis ease as judged by a physician and the presence of raised $\mathrm{C}$ reactive protein level. Approval was obtaine đ $^{+}$ for the study from the local ethical committee for medical research. The patients continued to tak $\oint_{0}^{\circ}$ their non-steroidal anti-inflammatory and analgesie therapy throughout the trial. They were all ine patients at the Regional Rheumatology Centre i⿺ Harrogate, with the exception of the three younges 
women in study 1 . In both studies the patients were age and sex matched with normal healthy controls. The demographic data for these subjects are shown in Table 1 .

Subjects starved from $10.00 \mathrm{pm}$ the previous night but were allowed water and their usual medication. Dietary restrictions were lifted three hours after dosing. Smokers were asked to refrain from smoking until the end of the sampling on the study days. All drugs were administered with patients in the upright position.

\section{STU DY 1}

Thirteen normal healthy volunteers and 13 patients with active RA took a $100 \mathrm{mg} \mathrm{kg}^{-1}$ L-histidine dose as an aqueous slurry at 9.00 am on the study day. The L-histidine used was the free base (AnalaR grade) obtained from British Drug Houses (BDH, Atherstone, UK). Venous blood samples $(10 \mathrm{ml})$ were taken by means of an indwelling cannula at times $0,15,30,40,50,60,70,80,90$ minutes and 2 , $3,4,6$, and 8 hours relative to the dose. The samples were allowed to clot in plain glass tubes at room temperature and then centrifuged at $550 \mathrm{~g}$ for 10 minutes within two hours of clotting. The serum was pipetted into a separate plastic tube and stored at $-20^{\circ} \mathrm{C}$ before analysis.

S T U D Y 2

Six female patients with RA and six healthy female controls each received a $50 \mathrm{mg} \mathrm{kg}{ }^{-1}$ body weight oral histidine bolus (as an aqueous slurry), and 50 $\mathrm{mg} \mathrm{kg}^{-1}$ body weight intravenous (IV) solution. The two doses were separated by seven to eight days. In each group the dosing order was random.

Each subject was given a single oral dose of mepyramine $(100 \mathrm{mg})$ before each dose of histidine to prevent any local inflammatory reaction at the site of entry of the infusion. It was given with the oral dose also to standardise trial conditions on both occasions. The intravenous solution $\left(35 \mathrm{mg} \mathrm{ml}^{-1} \mathrm{~L}\right.$ histidine) was prepared and packed by the drug manufacturing department at St James's Hospital, Leeds. The solution was administered at a mean rate of $154 \mathrm{ml} \mathrm{h}^{-1}$ (range $99-223 \mathrm{ml} \mathrm{h}^{-1}$ ) using a paediatric giving set which allowed an accurate amount to be given, though this resulted in a long infusion.

An intravenous cannula from which blood samples were taken was inserted into a forearm vein contralateral to the infusion. After the oral dose, blood samples $(10 \mathrm{ml})$ were taken at $0,10,20,30$, $40,50,60,75,90,105,120,150,180,240,300,360$, and 480 minutes. For the IV dose, samples were taken at 10 minute intervals until the end of the infusion, and then at $5,10,15,25,35,45,60,75,90$, $105,120,150,180,210,240,270$, and 300 minutes. Samples were treated and stored as described for study 1 .

\section{LABORATORY ASSESSMENTS}

Total serum histidine concentration was assayed by a modification of the method of Gerber $^{8}{ }^{9}$ employing a Perkin Elmer LS3 spectrofluorimeter. A six point calibration $\left(10-200 \mathrm{mg} \mathrm{l}^{-1}\right)$ was employed with precision ranging from $8.3 \%$ to $0.4 \%$ (mean $2.6 \%$ ) and accuracy from $93.0 \%$ to $101.8 \%$. The average recovery was 95 (SEM 2.7)\%. Quality control samples were included in every analytical run, with the run being rejected if the results for the control samples were $10 \%$ more or less than the previously determined value. Further details relating to the assay and sample storage are given elsewhere. ${ }^{9}$

PHARMACOKINETIC ANALYSIS

Model dependent

Individual data sets were best fitted, using

Table 1 Mean data (SEM) for healthy controls and patients with $R A$ in study 1 ( $n=13)$

\begin{tabular}{|c|c|c|c|}
\hline Parameter & $R A$ & Control & p Value \\
\hline $\operatorname{Sex}(F: M)$ & $9: 4$ & $9: 4$ & - \\
\hline Age (years) & $40 \quad(4)$ & $39 \quad(4)$ & NS \\
\hline Weight (kg) & (3) & (2) & $<0.02$ \\
\hline Dose $(\mathrm{g})$ & $5 \cdot 5 \quad(0 \cdot 27)$ & $6 \cdot 4 \quad(0 \cdot 19)$ & $<0.02$ \\
\hline \multicolumn{4}{|l|}{ Initial, baseline } \\
\hline histidine $\left(\mathrm{mg} \mathrm{l}^{-1}\right)$ & $15 \cdot 0 \quad(0 \cdot 7)$ & $18 \cdot 0 \quad(0 \cdot 7)$ & $<0.007$ \\
\hline $\mathrm{C}_{\max }\left(\mathrm{mg}^{-1}\right)$ & 134 & $158 \quad(5)$ & $<0.016$ \\
\hline$T_{\max }(h)$ & $0.72(0.05)$ & $0.72(0.04)$ & NS \\
\hline$t_{1 / 2}(h)$ & $1 \cdot 18(0 \cdot 16)$ & $1.69(0.19)$ & $<0.05$ \\
\hline $\operatorname{AUC}_{0-\infty}\left(\mathrm{mg} \mathrm{l}^{-1} \mathrm{~h}\right)$ & $312 \quad$ (44) & $477 \quad(49)$ & $<0.02$ \\
\hline
\end{tabular}

NS $=$ not significant, $\mathrm{p}>0 \cdot 05$.

$C_{\max }=$ maximum serum histidine concentration; $T_{\max }=$ time to achieve $C_{\max } ; t_{1 / 2}=$ serum histidine half life; $A U C=$ area under the serum concentration versus time curve. 
ELSMOS, ${ }^{10}$ to a one compartment model having first order absorption and first order elimination superimposed on a constant rate input equal to the rate of output under basal conditions. If basal serum level $=\mathrm{s}_{0}\left(\mathrm{mg} \mathrm{l}^{-1}\right)$, volume $=\mathrm{V}(1)$, and elimination rate constant $=k e\left(h^{-1}\right)$ then the rate of output $=\mathrm{s}_{0} \times \mathrm{V} \times \mathrm{ke}=$ rate of input $=\left(\mathrm{mg} \mathrm{h}^{-1}\right)$. When dosed with the drug, input $=\mathrm{s}_{0} \times \mathrm{V} \times \mathrm{ke}+\mathrm{A}$, where for the IV dose $A=$ dose/infusion time and for the oral dose $A=f \times$ dose $\times k a$, where $f=f r a c t i o n$ of dose remaining to be absorbed and $\mathrm{ka}=$ absorption rate constant. For the oral dose $\mathrm{A}=0$ during the time lag before absorption starts. Output $=s \times V \times k e$, where $\mathrm{s}=$ serum histidine level.

All data sets were fitted to this model and the best values of $s_{0}, V$, and ke were found together with ka for oral doses. All sets gave an acceptable fit, though $\mathrm{s}_{0}$ differed in some cases from the measured value. Clearance was calculated as $\operatorname{ke} \times \mathrm{V}\left(1 \mathrm{~h}^{-1}\right)$. Basal flux (or turnover) (F1) was $\mathrm{ke} \times \mathrm{V} \times \mathrm{s}_{0}$ (mg $\mathrm{h}^{-1}$ ) from IV data. Bioavailability (\%) was calculated as $100 \times \mathrm{Cl}$ (IV)/Cl (oral) and $\mathrm{t}_{1 / 2}$ as $1 \mathrm{n} 2 / \mathrm{ke}$, where $\mathrm{Cl}=$ total body clearance.

\section{Model independent}

Computer modelling showed that the data most closely fitted a one compartment model with first order elimination. Maximum serum histidine concentration $\left(C_{\max }\right)$ and time to achieve $C_{\max }\left(T_{\max }\right)$ were observed directly from the data. (In the case of IV dosing $\mathrm{C}_{\max }$ was the concentration at the completion of the infusion.) The serum histidine half life $\left(t_{1 / 2}\right)$ was obtained by log linear least squares regression analysis of data points following the peak concentration, after subtraction of the baseline histidine concentration from each result.

The area under the serum concentration versus time plot $\left(\mathrm{AUC}_{0-\infty}\right)$ was calculated using the trapezoidal rule. As the AUC was required to determine bioavailability the initial baseline hist dine concentration was subtracted from the tot concentration at each time point. The apparer volume of distribution $\left(V_{D}\right)$ was calculated fron

$$
\mathrm{V}_{\mathrm{D}}=\frac{\mathrm{D} \times \mathrm{t}_{1 / 2}}{\mathrm{AUC}_{0-\infty} \times \ln 2}
$$

where $\mathrm{D}=$ dose and complete drug bioavailability after an IV dose is assumed. Total body clearance (Cl) was determined from $\mathrm{D} / \mathrm{AUC}_{0-\infty}$.

\section{STATISTICAL ANALYSIS}

An unpaired two sample $t$ test (two tailed) was used to compare the pharmacokinetic data for patienfo and controls in both studies.

\section{Results}

\section{S T U D Y 1}

The kinetic results are summarised in Table Predose serum histidine concentrations were signiffo cantly lower in the patients. When patients and controls were compared the patients showed o significantly lower $\mathrm{C}_{\max }$, shorter $\mathrm{t}_{1 / 2}$, and smalle $\mathrm{AUC}_{0-\infty}$. Dose and hence body weight correlate significantly $(\mathrm{p}<0.001)$ with $\mathrm{C}_{\max }$ and $\mathrm{AUC}_{0-\infty}$ b传 not with $t_{1 / 2}$ in both patients and controls.

\section{STUDY 2}

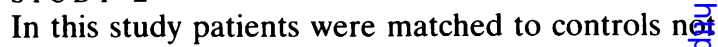
only for age and sex but also for body weight, and hence for dose. Although the absolute resulis generated by the model dependent (Table 2) ang model independent (Table 3) analyses were nơt identical, the trends in the differences betwegn patients and controls were the same. There were

Table 2 Summary of model dependent pharmacokinetic parameters in study $2 *$

\begin{tabular}{|c|c|c|c|c|}
\hline \multirow[t]{2}{*}{ Parameters } & \multicolumn{2}{|l|}{ Oral dose } & \multicolumn{2}{|l|}{ IV dose } \\
\hline & Controls & $R A$ & Controls & $R A$ \\
\hline \multicolumn{5}{|l|}{ Fitted coefficients } \\
\hline $\mathbf{k a}\left(\mathrm{h}^{-1}\right)$ & $3 \cdot 07(0 \cdot 40)$ & $3.89 \quad(1.61)$ & & 一 \\
\hline ke $\left(h^{-1}\right)$ & $1 \cdot 04(0 \cdot 27)$ & $1 \cdot 19(0 \cdot 20)$ & $0.96 \quad(0.24)$ & $1.28 \quad(0.14)$ \\
\hline$V(1)$ & $31 \cdot 3(3 \cdot 2)$ & $25 \cdot 8(3 \cdot 0)$ & $27.9 \quad(3.5)$ & $20 \cdot 6 \quad(1.7)$ \\
\hline $\mathrm{s}_{0}\left(\mathrm{mg} \mathrm{l}^{-1}\right)$ & $20.2(0.9$ & $17 \cdot 3 \quad(1 \cdot 0)$ & $20 \cdot 4 \quad(2 \cdot 2)$ & $19 \cdot 4 \quad(1.5)$ \\
\hline \multicolumn{5}{|l|}{ Calculated parameters } \\
\hline $\mathrm{Cl}\left(1 \mathrm{~h}^{-1}\right)$ & $29 \cdot 2(5 \cdot 1)$ & $29 \cdot 1 \quad(4 \cdot 1)$ & $23 \cdot 5 \quad(2 \cdot 7)$ & $25 \cdot 9 \quad(3.0)$ \\
\hline $\mathrm{Fl}\left(\mathrm{mg} \mathrm{h}^{-1}\right)$ & - & - & $485(90)$ & $494(61)$ \\
\hline$t_{1 / 2}(h)$ & $0.88(0.18)$ & $0.68 \quad(0.13)$ & $0.89 \quad(0 \cdot 15)$ & $0.59 \quad(0.10)$ \\
\hline Bioavailability (\%) & $86 \cdot 3(8 \cdot 3)$ & $97.8(18.7)$ & - & - \\
\hline \multicolumn{5}{|c|}{ *Values are mean (SEM). } \\
\hline
\end{tabular}


Table 3 Summary of model independent pharmacokinetic parameters in study 2*

\begin{tabular}{|c|c|c|c|c|}
\hline \multirow[t]{2}{*}{ Parameters } & \multicolumn{2}{|l|}{ Oral dose } & \multicolumn{2}{|l|}{$I V$ dose } \\
\hline & Controls & $R A$ & Controls & $R A$ \\
\hline Baseline histidine $\left(\mathrm{mg} \mathrm{l}^{-1}\right)$ & $15 \cdot 4 \quad(0 \cdot 9)$ & $14 \cdot 8 \quad(1 \cdot 7)$ & $15 \cdot 7 \quad(0 \cdot 6)$ & $14.6 \quad(1.2)$ \\
\hline $\mathrm{C}_{\max }\left(\mathrm{mg} \mathrm{l}^{-1}\right)$ & $73 \cdot 1 \quad(6 \cdot 6)$ & $90.1 \quad(6.9)$ & $92 \cdot 4(14 \cdot 3)$ & $114 \cdot 8 \quad(6 \cdot 7)$ \\
\hline$t_{1 / 2}(h)$ & $1 \cdot 14 \quad(0 \cdot 13)$ & $1.02(0.16)$ & $1.02 \quad(0.17)$ & $0.75 \quad(0.13)$ \\
\hline $\operatorname{AUC}_{0-\infty}\left(\mathrm{mg} \mathrm{l}^{-1} \mathrm{~h}\right)$ & $142(18)$ & $178(39)$ & $181(23)$ & $190(30)$ \\
\hline$V_{D}\left(\mathbf{k g}^{-1}\right)$ & - & - & $0.418 \quad(0.06)$ & $0.284 \quad(0.01)$ \\
\hline $\mathrm{Cl}\left(\mathrm{lh}^{-1}\right)$ & - & - & $19.0 \quad(3.09)$ & $19.0(1.93)$ \\
\hline Bioavailability (\%) & $80 \quad(9.9)$ & $91 \quad(5 \cdot 1)$ & - & - \\
\hline
\end{tabular}

*Values are mean (SEM).

statistically significant differences between patients and controls for any kinetic parameter, using either the model dependent or model independent results. The improved matching showed similar $\mathrm{AUC}_{0-\infty}$ results in patients and controls after both oral and IV doses, but the bioavailability was found to be quite variable $(52-111 \%)$ (Tables 2 and 3 ). The serum $t_{1 / 2}$ was shorter and the $C_{\max }$ higher in patients than in the controls after oral and IV doses. $V_{D}$ was notably lower in five of the six patients, while $\mathrm{Cl}$ showed no difference. There was no significant correlation between dose and any kinetic parameter.

\section{Discussion}

Some of the kinetic differences between patients with RA and normal controls observed in the first study may be attributed to the differences in body weight (e.g. $\left.\mathrm{AUC}_{0-\infty}\right)$. Although the dose was titrated against body weight, this could have confounded the results from this study as the differences might be explained on the basis of the different doses. In the second study the two groups were matched for weight in addition to age and sex, and hence the trends observed in the results might be more reliably attributed to disease. Differences in baseline histidine and $t_{1 / 2}$ seen in the first study were maintained in the second study, but with the small number of patients in the latter it was not surprising that these failed to achieve statistical significance.

Bioavailability was variable though slightly greater in RA, suggesting an absence of abnormal histidine absorption in RA. These results do not exclude the possibility that patients with RA may have difficulty digesting protein such that low net histidine absorption arises. Concentrations of histidine in the bowel will clearly usually be lower than those achieved in these studies.

The major kinetic difference observed was a smaller $V_{D}$, resulting in a shorter serum $t_{1 / 2}$ in patients. The smaller volume cleared at the same rate would take less time, and this is compatible with identical clearance results in the two groups. The differences in $V_{D}$ are not readily explained, but differences in non-specific histidine binding may be considered. In RA there are changes in protein concentrations, particularly the acute phase proteins. Some basic drugs, e.g., propranolol, are known to bind to $\alpha_{1}$ acid glycoprotein, and so a basic amino acid such as histidine may also bind to an acidic acute phase protein. Changes in protein conformation may also occur in RA, which could affect the binding capacity. This point may be further complicated by the presence of bound anti-inflammatory drugs in the patients. Alternatively, there may be a decrease in tissue binding of histidine arising from displacement by drugs, though the $V_{D}$ results are small in both groups, suggesting limited tissue uptake. Increased urine concentrations of urocanic acid have been observed in RA, and these were considered to be related to pyridoxine deficiency (pyridoxal phosphate is an essential cofactor for urocanase) rather than to folate status. ${ }^{11}$ Our results indicate that this failure of patients to degrade histidine fully does not affect its clearance.

There remains the possibility that if a different amino acid was used in a similar loading study that similar results might be obtained in the absence of a difference in baseline levels. Future studies should therefore include a loading study similar to study 2 using an amino acid which shows normal serum levels in RA. To be certain in the selection of the latter, however, the levels of other amino acids in RA require confirmation as previous investigations have only agreed on abnormally low serum histidine. ${ }^{12-15}$

It can be concluded that there is a trend towards a reduction in the distribution volume of a histidine load in patients with RA. This occurs in conjunction with a reduction in serum half life but no change in clearance. There is no evidence for abnormal 


\section{Sitton, Dixon, Astbury, Francis, Bird, Wright}

histidine absorption or increased metabolism in RA, but the precise cause of low serum histidine remains obscure.

The authors wish to thank Dr M R Lee, Dr M E Pickup. Dr J G Allen, Dr P E O Williams, and $\operatorname{Dr} \mathrm{N}$ Roberts for helpful discussion, and Mrs R Schofield for secretarial assistance. We acknowledge the financial support of the Arthritis and Rheumatism Council and Roche Products Limited.

\section{References}

1 Gerber D A. Gerber M G. Specificity of a low free serum histidine concentration for rheumatoid arthritis. $J$ Chronic Dis 1977; 30: 115-27.

2 Olhagen B, Mansson I. Intestinal Clostridium perfringens in rheumatoid arthritis and other collagen diseases. Acta Med Scand 1986; 184: 395-402.

3 Shinebaum R, Neumann V, Wright V, Cooke E M. Comparison of faecal flora of patients with rheumatoid arthritis and controls [Abstract]. J Med Microbiol 1984; 18: Abstr IV.

4 Body M J, Cogan M A, Tylett A A. The growth requirements of Clostridium perfringens (Welchii) BP6K. J Biol Chem 1948: 174: 1013-25.

5 Bergstrom K. Havermark G. Enzymes in testinal mucosa from patients with rheumatoid disease. Scand J Rheumatol 1976; 5: 29-32.

6 Udenfriend S, Lovenberg W M. Weisbach H. L-Amino acid decarboxylase activity in mammalian tissues and its inhibitiø日 by $\alpha$-methyl DOPA. Fed Proc 1960; 19: 7 .

7 Ropes M W. Bennett G A. Cobb S. Jacox R. Jessar R A. 19\$3 revision of diagnostic criteria for rheumatoid arthritis. Arthri. Rheum 1959; 2: 16-20.

8 Gerber D A. Determination of histidine in serum with phthaldialdehyde. Anal Biochem 1970: 34: 500-4.

9 Sitton N G. An investigation into the cause and specificity low serum histidine in rheumatoid arthritis. University Leeds, 1986. (PhD thesis).

10 Francis R J. ELSMOS-an extended least squares modelli $\vec{\square}$ system in Fortran IV for mini or micro computer implementi tion. Computer Programs in Biomedicine 1984; 18: 43-9. $\vec{\omega}$

11 Omer A. Mowat A G. Nature of anaemia in rheumat通 arthritis. IX. Folate metabolism in patients with rheumateीd arthritis. Ann Rheum Dis 1968; 27: 414-24.

12 Armstrong J J B. Bocking D, Derrick J B. Studies on ami花 acid metabolism in rheumatoid arthritis and ankylosing spondw litis. Arthritis Rheum 1962; 5: 635.

13 Gerber D A. Decreased concentration of free histidine in seruif in rheumatoid arthritis, an isolated amino acid abnormality not associated with generalised hypoaminoacidemia. $J$ Rheumatel 1975; 2: 384-92.

14 Nettelbladt E, Sandell B-M. Amino acid content of serum 量 rheumatoid arthritis. Ann Rheum Dis 1963: 22: 267-72.

15 Brodie E C. Wallraff E B, Borden A L, et al. Urinary excretion of certain amino acids during ACTH and cortisone treatment rheumatoid arthritis. Proc Soc Exp Biol Med 1950; 75: 285-o 